\title{
- La Argentina y los nuevos (viejos) dilemas de la inserción internacional: acuerdos de libre comercio o fortalecimiento del mercado interno con proyección regional
}

Damián Paikin ${ }^{*}$ Daniela Perrotta**

\section{Introducción}

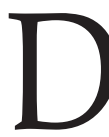
urante el bienio 2014-2015 los procesos electorales sudamericanos comenzaron a mostrar signos de un cierto agotamiento de los movimientos políticos surgidos a comienzos de los años 2000, con especial impacto en la victoria de la alianza Cambiemos con Mauricio Macri en la Argentina, el contundente triunfo de la oposición anti chavista en las elecciones legislativas de Venezuela, la reconfiguración del apoyo al gobierno de Dilma Rousseff y la derrota del referéndum pro relección propuesto por Evo Morales en Bolivia, apenas poco más de un año después de que el propio Morales consiguiera alcanzar por tercera vez la presidencia con más del $60 \%$ de los votos.

$\mathrm{Al}$ mismo tiempo, este proceso está siendo acompañado por el agotamiento del súper ciclo económico que experimentaron los países sudamericanos, en tanto el boom de las commodities se encuentra en descenso a partir de la reducción de los precios de estos productos de exportación y la desaceleración de la demanda China.

Consecuentemente, como en tantas otras ocasiones, el espectro político y económico sudamericano parece moverse en espejo, pivoteando entre ciclos nacionalistas y neoliberales (con matices entre ambos)

* Investigador. Centro de Estudios de la Estructura Económica (CENES), Instituto de Investigaciones Económicas, Universidad de Buenos Aires, Argentina; ‘dpaikin@yahoo.com〉.

** Investigadora Asistente. Consejo Nacional de Investigaciones Científicas y Tecnológicas (CONICET), Universidad de Buenos Aires, Argentina; «danielaperrotta@gmail.com». 
que generan, a partir de lógicas variantes según cada país, patrones comunes que pueden marcar etapas claras en el subcontinente, incluyendo en ellas las modalidades preferidas de encaminar el regionalismo. Así, la década perdida -en términos económicos- de los años ochenta fue seguida por la década neoliberal durante los años noventa en la cual América Latina pareció optar por la experiencia de inserción internacional conocida como nuevo regionalismo ${ }^{3}$ o regionalismo abierto. ${ }^{4}$

La crisis del neoliberalismo dio paso a un nuevo momento desde comienzos de los años 2000 basado en un espíritu neodesarrollista en el que se encolumnaron la mayoría de los países del subcontinente y que marcó la impronta continental con características autonómicas de esos años. Este momento propio de Sudamérica fue catalogado como post liberal $^{5}$ o post hegemónico. ${ }^{6}$

Sin embargo, pese a dicha hegemonía, durante toda la década se asistió en la región a una fuerte tensión, tamizada de momentos de acuerdos, en relación particularmente a las lógicas de inserción internacional a nivel comercial e incluso su correlato en términos políticos. Dos modelos en pugna sobrevolaron el continente desde aquel 5 de noviembre de 2005, cuando la Cumbre de las Américas de Mar del Plata culminó con el proyecto de la Asociación de Libre Comercio de las Américas (ALCA). En aquel momento, los países del MERCOSUR lograron proclamar un modelo de integración positiva ${ }^{7}$ ajeno a las lógicas de los acuerdos de libre comercio, al que años después complemen-

3. BID, El nuevo regionalismo en América Latina, en Banco Interamericano de Desarrollo, edit., Mas allá de las fronteras: el nuevo regionalismo en América latina.

4. CEPAL, Transformación productiva con equidad. La tarea prioritaria de América Latina y el Caribe en los años noventa. (Santiago de Chile: CEPAL, 1990): 7.

5. Pedro da Motta Veiga y Sandra Ríos, O regionalismo pós-liberal, na América do Sul: origens, iniciativas e dilemas. (Santiago de Chile: CEPAL, 2007). José Antonio Sanahuja, “Del 'regionalismo abierto' al 'regionalismo post liberal'. Crisis y cambio en la integración en América Latina y el Caribe", en Laneydi Martínez, Lázaro Peña y Mariana Vazquez, eds., Anuario de la integración regional de América Latina y el Gran Caribe 2008-2009. (Buenos Aires: Coordinadora Regional de Investigaciones Económicas y Sociales-CRIES, 2008). Antonio Sanahuja, "Post-liberal Regionalism in South America: The case of UNASUR", RSCAS 5 (2012): 1-31.

6. Pia Riggirozzi y Diana Tussie, "The Rise of Post-Hegemonic Regionalism in Latin America" en Pia Riggirozzi y Diana Tussie eds., The Rise of Post-Hegemonic Regionalism. The case of Latin America. (Dordrecht: Springer, 2012): 1-16.

7. Se entiende por integración positiva aquella generada a partir de políticas distributivas; mientras que la negativa refiere a la eliminación de barreras al comercio. 
taron con otras iniciativas unitarias volcadas principalmente a darle carnadura al concepto de autonomía política como fueron la Unión de Naciones Sudamericanas (UNASUR), en el años 2008 y posteriormente la Comunidad de Estados Latinoamericanos y Caribeños (CELAC), en el 2011. ${ }^{8}$

Ahora bien, todos los países sudamegrado de participación. Sin quedar por fuera de ellos en ningún caso, se aceptaron, incluso, los planteos anti-norteamericanos de dichos procesos: por ejemplo, la utilización de la UNASUR como espacio para resolver los problemas relacionados con la paz y la democracia en detrimento de la Organización de Estados Americanos (OEA) o la inclusión de Cuba en la CELAC. Pero mientras esta convergencia política sucedía, los países del Pacífico, con la excepción de Ecuador, fueron paulatinamente reforzando un modelo de inserción internacional que, primero, en solitario (bilateralmente) y luego coordinadamente, fue fortaleciendo la construcción de un patrón regional basado en el libre comercio (conforme la senda de nuevo regionalismo que habían iniciado durante los años noventa, especialmente enfocada en la firma de acuerdos comerciales bilaterales asimétricos).

Consecuentemente, atrás de Chile -con un esquema ininterrumpido de apertura de su economía desde los años setenta, durante la dictadura de Pinochet, hasta los gobiernos de la Democracia Cristiana y los socialistas-, Colombia y Perú se volcaron a la firma de acuerdos comerciales bilaterales de características asimétricas ${ }^{9}$ con terceros países, especialmente con los Estados Unidos y la Unión Europea. Esta estrategia unilateral, fomentada tras el fracaso de las negociaciones del ALCA,

8. En otros trabajos hemos abordado los tres proyectos de construcción de región que se abrieron a partir del rechazo a la negociación del ALCA. A los dos aquí mencionados, se suma un tercer ensayo promovido por Venezuela y Cuba como estrategia de integración más radical, evitando la lógica del intercambio comercial para pasar al intercambio basado en la reciprocidad y solidaridad. Nos referimos a la Alternativa Bolivariana para los Pueblos de Nuestra América -Tratado de Comercio de los Pueblos (ALBA-TCP).

9. Se refiere a aquellos acuerdos firmados por países de diferentes niveles de desarrollo relativo. 
tuvo como consecuencia la implosión del proceso de integración regional más antiguo de Sudamérica, la Comunidad Andina (CAN) ya que las diferencias entre sus socios se tornaron complejas para resolver y canalizarse en el marco del sistema andino de integración. Precisamente, a raíz de estas diferencias se entiende la solicitud de Venezuela, primero, y de Bolivia y Ecuador, luego, de adhesión como miembro pleno al MERCOSUR.

No obstante, tras el debilitamiento de la CAN, surge en su lugar otro espacio regional: la Alianza del Pacífico, integrada por Chile, Perú, Colombia y México. La incorporación de México -miembro del Tratado de Libre Comercio de América del Norte (TLCAN o NAFTA, según su nombre en inglés) en 1994- resulta interesante porque, tal como afirma Carlos Malamud (2012), la discusión Sudamérica/América Latina que recorrió los procesos de integración durante la primera década del siglo XXI, fue superada por la fuerza de los hechos al incluirse a México antes que por su lugar geográfico, por su definición en torno a la relación con los Estados Unidos y su prédica pro libre comercio.

La política de la Alianza del Pacífico es contundente respecto a la forma preferida de inserción internacional: apertura económica, especialización y utilización del comercio internacional como proveedor de divisas así como regulador de los precios internos de la economía, sumado a condiciones amigables con la inversión extranjera, entendiéndola como el motor principal del desarrollo.

Con la conformación de la Alianza del Pacífico se reavivaron los pedidos de búsqueda de convergencia con el MERCOSUR, encontrando eco, especialmente, en aquellos sectores que presionan por un MERCOSUR con mayor flexibilidad negociadora y apertura a la firma de TLC con terceros países o grupos de países. Rápidamente, la Alianza se volvió atractiva para los sectores conservadores de los países atlánticos (e, incluso, para algunos fragmentos de los sectores progresistas) en virtud de al menos dos cuestiones. Por un lado, algunos números concretos y positivos de las macroeconomías de dichos países que destacan el modelo de inserción como beneficioso. Por el otro, ciertos mitos -que de tan repetidos pasan a ser dogmas- sostenidos sobre todo en la idea, ajena en ocasiones a la realidad, que indica que una vinculación amigable con los Estados Unidos ubica al país del lado de los triunfadores de la globalización. 


\section{La nueva visión del gobierno argentino}

En este marco comentado anteriormente las primeras afirmaciones del nuevo gobierno argentino en materia de política exterior dan cuenta de esta situación de tensión entre las distintas formas de encaminar la inserción económica internacional del país. El primer viaje del presidente Mauricio Macri a Brasil así como su planteo de reforzar el MERCOSUR y culminar con el proceso de negociación conjunta con la Unión Europea (UE), son señales que chocan permanentemente con la también anunciada voluntad de sumar a la Argentina a la Alianza del Pacífico, bajo la idea expuesta por la Canciller Susana Malcorra de no desperdiciar el vínculo con esa zona geográfica y también como puerta de entrada al Tratado de Asociación Transpacífico (TTP, de acuerdo a su nombre en inglés); buscando oportunidades comerciales en los dos océanos. ${ }^{10}$

Ahora bien, el lema expresado tanto por Macri como por la Canciller Malcorra de integrar a Argentina a la Alianza del Pacífico desde el MERCOSUR, ${ }^{11}$ viene a cerrar el cisma de la segunda mitad de los años $2000^{12}$ y plantea un escenario de encuentro interesante que merece ser

10. Susana Malcorra sostuvo en el Council on Foreign Relations (un think tank de los Estados Unidos) el 9 de febrero de 2016 que "el objetivo a corto plazo es fortalecer la oportunidad entre el MERCOSUR y la Unión Europea (UE). Esta es una tarea pendiente hace mucho tiempo y hay que cerrar la operación. Finalmente, el MERCOSUR está listo para hacerlo [...] Así que, para nosotros, la UE es históricamente muy importante. Desde la perspectiva comercial es un socio muy importante. $Y$ eso es lo que hemos priorizado. Una vez que eso esté en marcha, vamos a empezar a buscar en el Pacífico y vamos a ver si el TPP es la siguiente fase o tenemos que firmar algunos acuerdos bilaterales primero. Se puede construir de diferentes maneras, sin duda. Pero, para nosotros, Pacífico y Atlántico, Atlántico y Pacífico son una respuesta a nuestras necesidades, sin lugar a dudas" (Argentinian Foreign Policy Under Mauricio Macri. The Future of Argentina: A Conversation with Susana Mabel Malcorra entrevista realizada por Shannon K. O'Neil; traducción de los autores del trabajo). La entrevista completa se encuentra disponible en: ‘http:/ / www.cfr.org/argentina/argentinian-foreign-policy-under-mauricio-macri/p37519> [Último acceso, 12 de marzo de 2016].

11. "La integración de Argentina con la Alianza del Pacífico debe darse desde el Mercosur", Minuto uno, 18 enero, 2016, https:/ / www.minutouno.com/notas/1465217-la-integracion-argentina-la-alianza-del-pacifico-debe-darse-el-mercosur».

12. En efecto, en la antesala de la creación de la Unión de Naciones Suramericanas (UNASUR) cuando aún el proyecto regional tenía el nombre de Conferencia de Naciones Sudamericanas (CNS), el objetivo económico de la conformación de este espacio regional consistía en la convergencia comercial entre la CAN y el MERCOSUR -meta que podemos rastrear hasta la propuesta de Itamar Franco de encaminar un área de libre comercio de América del Sur (ALCSA) de los años noventa, como estrategia defensiva frente al ALCA-. No obstante, entre uno de los motivos que explican la creación de la UNASUR se encuentra el dejar de lado la búsqueda de convergencia comercial entre el acuerdo regional atlántico y el andino. 
revisado desde al menos dos ámbitos. El primero, de tipo formal legal: ¿sería posible la pertenencia a estos dos esquemas de integración? Ciertamente, el mundo de la política permite encontrar soluciones imaginativas a diversos conflictos, pero, en ocasiones, esto se vuelve imposible, tal como fue el caso del pedido de ingreso de Bolivia al MERCOSUR en el año 2006 sin abandonar la CAN. En esa ocasión, la existencia de dos uniones aduaneras, con sus acervos normativos separados generó enormes dificultades para hallar un camino de convivencia. ¿Será este un caso similar o se podrá convivir sin mayores inconvenientes como lo hace, por ejemplo, la pertenencia a la UNASUR y al MERCOSUR?

El segundo ámbito de análisis a tener en cuenta, por su parte, es el siguiente: en caso de que fuera posible, ¿en que se beneficiaría concretamente la Argentina con su incorporación a dicha Alianza? Evidentemente la realización de un análisis prospectivo de sectores y potencialidades de mercados a beneficiarse escapa al objeto de este trabajo, pero en cambio sí es posible realizar un pequeño ejercicio comparativo y observar en qué medida y a que sectores de los países miembros de la Alianza del Pacífico benefició dicho acuerdo, planteando algunas líneas de lo que podría pasar en virtud de lo analizado en la Argentina.

En definitiva entonces analizar las posibilidades legales y económicas de un ingreso de la Argentina a la Alianza del Pacífico desde el MERCOSUR, planteado por el gobierno de Mauricio Macri es el objeto principal de este documento para lo cual se trabajará en dos secciones diferenciadas (la primera desde una mirada de tipo legal institucional y la segunda con un fuerte sesgo comercial), dejando una tercera para las conclusiones del caso.

\section{Entre el spaghetti bowl, la superposición y la incompatibilidad}

Las posibles pertenencias a más de un acuerdo comercial de integración

El primer nivel de análisis para evaluar las posibilidades de Argentina para formar parte de la Alianza del Pacífico y, eventualmente, de un acuerdo que alcanza más países como el TPP, requiere observar la situación de múltiples membrecías a acuerdos regionales que sostiene el país $\mathrm{y}$, particularmente, las incompatibilidades que acarrea la pertenencia al MERCOSUR. Esta situación remite a indagar las diferentes discusiones 
que se sucedieron desde la explosión del fenómeno del nuevo regionalismo a nivel global en los años noventa y su vinculación con el multilateralismo promovido por la Organización Mundial de Comercio (OMC) hasta la emergencia de una cartografía compleja y caracterizada por la superposición de proyectos de construcción de región en América del Sur, cuando promediaba la primera década del siglo XXI.

En la década de los años noventa, de manera unilateral, los países de América Latina comenzaron a implementar un proceso de reforma estructural del Estado que incorporaba como un componente central la promoción de la liberalización y desregulación de sus economías. Esto se expresó en la reducción de los aranceles y, con la creación de la OMC, la adopción de un arancel consolidado y la posibilidad de firmar tratados de libre comercio con países de disímil nivel de desarrollo (asimétricos) bajo la expectativa de que la liberalización comercial contribuiría a reducir niveles de pobreza y promover el crecimiento económico.

Así, comienzan a proliferar los TLC y una manera peculiar de encaminar la formación de regiones en lo que se conoce como nuevo regionalismo o regionalismo abierto, cuya característica central refiere a que el proceso de liberalización comercial se realiza entre los socios (intrazona) pero también hacia terceros países o grupos de países. Tal adjetivación de "abierto" alude a esta condición, en contraposición a experiencias pasadas de formación de región que se presuponían "cerradas", anacrónicas.

El nuevo regionalismo, de acuerdo a la Comisión Económica para América Latina (CEPAL) es:

el proceso que surge [...] de conciliar la interdependencia nacida de acuerdos especiales de carácter preferencial y aquella impulsada básicamente por las señales del mercado resultantes de la liberalización comercial en general [donde se pretende] que las políticas explícitas de integración sean compatibles con las políticas tendientes a elevar la competitividad internacional, y que las complementen; [...] siendo el elemento distintivo de los acuerdos de este tipo] la cercanía geográfica y la afinidad cultural de los países de la región. ${ }^{13}$

13. CEPAL, Transformación productiva con equidad. La tarea prioritaria de América Latina y el Caribe en los años noventa. (Santiago de Chile: CEPAL, 1990): 7. 
Así, las medidas de política que debían de ser adoptadas consistían en la reducción gradual de la discriminación intrarregional, la estabilización macroeconómica, el establecimiento de mecanismos adecuados de pago y de facilitación del comercio, la construcción de infraestructura, la armonización o aplicación no discriminatoria de normas comerciales, regulaciones internas y estándares y la reducción de los costos de transacción y de la discriminación al interior de la región por medio de políticas sectoriales. Más adelante en el tiempo, conforme se iban firmando diferentes TLC en todo el globo, el componente de cercanía geográfica y afinidad cultural entre los países, pasaría a ser dejado de lado.

Por su parte, el Banco Interamericano de Desarrollo (BID) consideró que la novedad del nuevo regionalismo resultaba de su composición interna y de su relación con el sistema de comercio regulado por la OMC. Respecto de la composición interna, se destaca la participación de Estados de diferentes niveles de desarrollo relativo (asimetría), sin incorporar previsiones para igualar esta situación. En lo que compete a la vinculación con la $\mathrm{OMC}$, el nuevo regionalismo plantea una relación de complementariedad con el multilateralismo (apertura). En sus términos, cinco son los objetivos de política que permiten ser alcanzado por medio del nuevo regionalismo: fortalecer las reformas económicas estructurales ("efecto candado"); transformar las economías latinoamericanas a partir de las oportunidades de exportación y diversificación de comercio, el acceso a los mercados y la especialización; atraer inversiones externas; promover la democracia; y aumentar el poder negociador de estos países en foros mundiales. ${ }^{14}$ De esta manera, en la promoción de acuerdos regionales de este tipo se van sumando intereses defensivos y ofensivos, así como valores e identidades.

Este tipo de proyectos regionales no requiere del desarrollo de un marco institucional denso, sino de las agencias regionales -mayoritariamente de carácter intergubernamental- con pericia en la implementación del esquema de liberalización arancelaria y de remoción de las barreras no arancelarias, así como de una estructura jurídica con mecanismos de solución de disputas que se generen entre las partes. En otras

14. BID, El nuevo regionalismo en América Latina, en Banco Interamericano de Desarrollo, edit., Mas allá de las fronteras: el nuevo regionalismo en América latina (Buenos Aires: BID, 2002): 27-62 
palabras, se trata de esquemas "livianos" ya que no se colocan como objetivo la integración de otras agendas no comerciales -desde integración productiva a políticas sociales-. No obstante, pese a no ser profundos, sí se trata de acuerdos amplios en términos de alcances ya que, conforme avanzaba la agenda comercial multilateral, estos acuerdos pasaron de regular solamente el intercambio de bienes a incorporar servicios, inversiones, derechos de propiedad intelectual y compras públicas.

Con todo, hacia fines de la década de los noventa e inicios de los años 2000, se tematizaba en torno de si los TLC y el regionalismo constituían un elemento que posibilitaba el multilateralismo o si bien contribuían a obstaculizarlo. En especial, a partir de los numerosos estudios sobre creación y desvío de comercio que vieron la luz en esos años. También así se abordó el fenómeno del spaghetti bowl (plato de espagueti), imagen que busca dar cuenta de la complejidad de las relaciones comerciales internacionales como consecuencia de la multiplicidad de acuerdos firmados entre los países de manera desordenada. ${ }^{15}$

La proliferación de acuerdos comerciales preferenciales ${ }^{16}$ no es, pues, la dificultad de fondo; sino que el problema es la coexistencia de una maraña de reglas preferenciales entrecruzadas sin disciplinas comunes multilaterales efectivas, que promueve la discriminación en lugar de los signos cooperativos que se atribuyen al sistema comercial internacional. ${ }^{17}$ Félix Peña (2007), desde un punto de vista pragmático, indica tres líneas de acción para la Argentina, a saber: primero, tener claridad del mapa de los tratamientos preferenciales que otros países se otorgan, y su incidencia en la competitividad relativa de bienes y servicios originados en el país. Segundo, articular una estrategia de negociaciones comerciales en función de intereses ofensivos (no sólo defensivos) de empresas y productores; lo que, a la vez, supone de la presencia

15. El autor que introduce el término es Jagdish Bhagwati en 1995; también abordado en Bhagwati y Panagariya (1999).

16. Hay 422 acuerdos comerciales regionales notificados a la OMC/GATT (Acuerdo General de Aranceles Aduaneros y Comercio). Ver: ‘https:/ / www.wto.org/english/res_e/statis_e/merch_ trade_stat_e.htm>.

17. Félix Peña, ¿Cuál es el verdadero problema del "spaghetti bowl"?: Proliferación de acuerdos preferenciales en un sistema comercial global debilitado, Newsletter sobre relaciones comerciales internacionales, abril (2007). 〈http://www.felixpena.com.ar/index.php?contenido=negociaciones\&neagno=informes/2007-04>. 
significativa de empresas con este tipo de estrategias en terceros mercados. Tercero, concertar estas acciones con los socios del MERCOSUR, a raíz del arancel externo común (AEC). Este punto es el que referiremos enseguida como una situación de incompatibilidad.

\section{Los límites del Mercosur}

La creación del MERCOSUR (26 de marzo de 1991) entre Argentina, Brasil, Paraguay y Uruguay fue anterior a la puesta en marcha de la OMC y posterior a la Asociación Latinoamericana de Integración (ALADI). El acuerdo fundacional (Tratado de Asunción) establecía la conformación de un mercado común -buscando asemejarse a la experiencia europea de integración-; no obstante, lo cierto es que al analizar los instrumentos que, efectivamente, fueron implementados por el MERCOSUR durante su primera década de funcionamiento, se optó por priorizar la agenda de liberalización comercial por sobre otros aspectos que hacen a una integración profunda. Esto permite comprenderlo como un esquema de tipo nuevo regionalismo.

El Tratado de Asunción (TA) estableció el programa de liberalización comercial con rebajas arancelarias progresivas, lineales y automáticas, junto a la reducción de barreras no arancelarias para alcanzar el arancel cero el 31 de diciembre de 1994 en la totalidad del universo arancelario. Meta que, a todas luces, pese a la existencia de listas nacionales (con productos exceptuados o con plazos mayores de desgravación según los países) se cumplió. El Protocolo de Ouro Preto (firmado en 1994) estableció el AEC -que comenzó a regir el 1 de enero de 1995creando la unión aduanera y regulando las relaciones comerciales de los Estados Parte con terceros países y grupos de países.

La estructura del AEC es de 0 a 20 puntos porcentuales, de manera escalonada cada 2 puntos porcentuales, reflejando la estructura tarifaria de Brasil, que tiende a proteger la producción de bienes industriales. En el transcurso de estos años, el sector del azúcar es excluido tanto de la intra como de la extra zona a raíz de las presiones de los productores argentinos frente a la competitividad del sector brasilero. Otro tema que tampoco forma parte, per se, del MERCOSUR es el acuerdo automotriz que se trata, eminentemente, de una situación de comercio administrado entre Argentina y Brasil. 
La ALADI fue creada en 1980 a partir de la firma del Tratado de Montevideo; actualmente está integrada por Argentina, Bolivia, Brasil, Chile, Colombia, Cuba, Ecuador, México, Panamá, Paraguay, Perú, Uruguay y Venezuela. Es un marco jurídico que permite que estos países puedan firmar diferentes instrumentos comerciales en pos de la conformación de un mercado común latinoamericano: preferencias arancelarias de alcance regional, acuerdos de alcance regional y acuerdos de alcance parcial. Previo a la conformación del MERCOSUR, los cuatro Estados Parte mantenían compromisos con los demás miembros de la ALADI. Es por ello que una vez creado el MERCOSUR, y habiendo optado por inscribirlo como un acuerdo parcial de complementación económica (ACE) -es el ACE No. 18 entre Argentina, Brasil, Paraguay y Uruguay (depositado el 29 de noviembre de 1991)- comienzan a negociar las preferencias comerciales con los demás socios de la ALADI. Este proceso conlleva a las primeras adhesiones que recibe el MERCOSUR: Chile, primero (en el año 1996) y Bolivia, luego (en el año 1998); países que adquieren el estatus de Estados Asociados al MERCOSUR y gozan de la zona de libre comercio (intra zona).

Por entonces, Chile venía desarrollando una estrategia de inserción internacional competitiva a partir de una política de arancel plano (del $6 \%)$ y de la búsqueda por acuerdos comerciales con la mayor cantidad posible de países o grupos de países (estrategia de actor global o global player). En vistas a este objetivo, Chile -que fue uno de los socios fundadores del Pacto Andino- denuncia el Tratado de Cartagena en 1976 cuando la política económica de la dictadura de Pinochet era contradictoria a las políticas de integración. Regresa a la CAN en el año 2006 pero como miembro asociado; es decir, para participar de los acuerdos comerciales al interior de la región andina.

En lo que compete a Bolivia, su condición primigenia de Estado Asociado también encuentra su explicación en la CAN, pero con otro motivo. La CAN es también -como el MERCOSUR- una unión aduanera: dada la teoría económica tradicional de la conformación de regiones, un acuerdo que implica la liberalización comercial entre los socios (intra zona) y la adopción de una política comercial común de la región para con otros actores (extra zona). La política comercial común implica la adopción de un AEC pero también la conformación de una aduana uni- 
ficada, de un código aduanero común y de la adopción de posiciones conjuntas en otros foros de negociación. Por lo tanto, resulta incompatible en términos legales (y hasta prácticos) para un país pertenecer en dos uniones aduaneras con AEC, dos códigos aduaneros y un problema de contabilización de aduanas.

En el año 2006 Bolivia, que ya era Estado asociado, solicitó ingresar de manera plena al MERCOSUR sin abandonar la CAN -que se encontraba en proceso de crisis a raíz de las diferencias ideológicas entre sus miembros que se orientaban a la firma de TLC asimétricos y Venezuela ya había denunciado el acuerdo y colocado la mirada en MERCOSURde 2006 ya que la balanza comercial boliviana se beneficiaba más con la CAN que con el MERCOSUR de entonces..$^{18}$ Por lo tanto, si un país del MERCOSUR quiere alcanzar un acuerdo comercial con un país -o grupo de países- "extra región" (como puede ser el caso Argentina relacionándose de manera unilateral con la Alianza del Pacífico) debe ser cuidadoso en caso de que esos acuerdos que alcance se superpongan y hasta vayan en contra del arancel externo común que tiene la región.

No obstante, además de la situación de incompatibilidad que generan las uniones aduaneras, el MERCOSUR cuenta con una cláusula que impide la negociación de sus Estados Parte con terceros países o grupos de países de manera aislada. En el año 2000 los cuatro países adoptan la decisión del Consejo del Mercado Común (CMC) No. 32/00 por la que se comprometen a "negociar en forma conjunta acuerdos de naturaleza comercial con terceros países o grupos de países extrazonas en los cuales se otorguen preferencias comerciales" y establecen que "a partir del 30 de junio del 2001 [...] no podrán firmar nuevos acuerdos preferenciales o acordar nuevas preferencias comerciales en acuerdos vigentes en el marco de la ALADI, que no hayan sido negociados por el Mercosur". Esta "norma cerrojo" permitió consolidar al bloque como una unión aduanera, pero también otorgó cierto "posicionamiento" de una identidad reforzada ante terceros países y se aseguraba que el bloque no se fragmentara a partir de la búsqueda de TLC. ${ }^{19}$

18. Pablo Stefanoni "Bolivia pidió ingresar al MERCOSUR" (Clarín, 22 de diciembre de 2006). 〈http:/ / edant.clarin.com/diario/2006/12/22/elmundo/i-04602.htm».

19. Daniela Perrotta y Emanuel Porcelli, "Mercosur 25 años: desafíos en su nueva etapa", Márgenes. Revista de Economía Política, No. 2 (2016): 51-86. 
La adopción de la decisión CMC No. 32/00 se entiende a partir del contexto de esos años: el desarrollo de las negociaciones del ALCA propuesto por los Estados Unidos y donde el MERCOSUR, pese a que no se encontraba obligado a hacerlo, decide una estrategia negociadora de consolidación de una posición regional para llevar a las diferentes reuniones. Si bien el momento de no retorno de la negociación del borrador del ALCA llegará entrado los años 2000, los países del MERCOSUR consideraron que debían obturar la posibilidad de que los Estados Unidos (u otro actor asimétrico; en efecto, en esos años también se negociaba un acuerdo comercial interregional con la UE) seduzca con preferencias comerciales a los socios y eso llevara a la implosión del bloque del Cono Sur.

Consecuentemente, en materia comercial, el MERCOSUR imposibilita jurídicamente la posibilidad a sus miembros plenos para negociar unilateralmente nuevas preferencias comerciales con terceros. Por este motivo, hace varios años ya, aquellos sectores económicos (generalmente concentrados) que se benefician de un esquema de inserción comercial aperturista -y los grupos políticos a estos vinculados- en los cuatro países, vienen introduciendo dos cuestiones centrales: la primera, dar marcha atrás con la unión aduanera del MERCOSUR -posición que se nutre del hecho de que los países perforan el AEC de diferentes formas además y el hecho de que no se ha avanzado en la conformación de una aduana que recoja y reparta los derechos arancelarios regionalmente, las dificultades de la implementación del código aduanero común y la persistencia del doble cobro del arancel-. Por estos motivos, se busca "sincerar" al MERCOSUR y convertirlo en una zona de libre comercio. La segunda cuestión refiere a que, ante la rigidez de la decisión CMC No. 32/00, se ha de dar paso a un MERCOSUR flexible que permita a cada socio establecer acuerdos comerciales de manera unilateral.

Otro elemento a destacar para comprender la múltiple pertenencia a acuerdos regionales de los países sudamericanos refiere a una situación que ha despertado nutridos análisis, ${ }^{20}$ refiere a que la cartografía

20. Laura Gomez-Mera y Andrea Molinari, "Overlapping institutions, learning, and dispute initiation in regional trade agreements: evidence from South America", International Studies Quarterly 58, No. 2 (2014): 269-281. Andres Malamud, Overlapping regionalism, no integration: conceptual issues and the Latin American experiences, RSCAS 20 (2013): 11-1. Daniela Perrotta, MERCOSUR Brand: regionalism and higher education. Trabajo presentado en Regionalism, Norm Diffusion and Social Policy: dealing with Old and New crises in Europe and Latin America. Berlin, 2013. 
de la integración latinoamericana y caribeña se caracteriza por la superposición de acuerdos.

En especial, la idea de superposición busca indicar la tendencia de los países de América Latina y el Caribe de formar múltiples estructuras y que carga con los escombros institucionales de los acuerdos que ha establecido a lo largo de la historia. No obstante, es menester balancear esta opinión con el señalamiento de que los proyectos de construcción de región presentes hoy difieren en términos de sus metas y de sus metodologías -quizás el caso más visible es la CELAC, que se trata más bien de un foro de concertación política de alto nivel más que un proceso que busque promover políticas de integración en diferentes áreas o agendas- y que, en aquellos casos donde se percibe una mayor superposición -puntualmente, el MERCOSUR y la UNASUR- ha habido una cierta división regional de las políticas que cada acuerdo adopta como emblemáticas. Por otro lado, es menester recordar que si bien la convergencia comercial entre el MERCOSUR, la CAN, Guyana y Surinam era uno de los objetivos que llevaron a la conformación de un proyecto sudamericano, la creación de la UNASUR se debe, en buena medida, a que la meta de convergencia comercial -dificultada por las diferencias de proyecto político ideológico entre los países- fue dejada de lado. Por lo tanto, un posible acercamiento para alcanzar un acuerdo comercial entre el MERCOSUR y la Alianza del Pacífico puede volver a contar con la UNASUR como foro negociador, a la vez que espacio comercial convergente.

Finalmente, al analizar los documentos fundacionales y de funcionamiento de la Alianza del Pacífico (creada en el año 2011) no se encontraron aspectos que den cuenta de la imposibilidad de sus socios a establecer acuerdos de preferencias arancelarias de manera unilateral. Esta ausencia de una cláusula cerrojo que vincula, a todas luces, con el hecho de que sus países miembros son todos actores globales que han encaminado la liberalización de sus relaciones externas en materia comercial. La Alianza declara como valor estratégico su apertura al libre comercio: los miembros mantienen una red de acuerdos comerciales entre sí y con las economías más desarrolladas y dinámicas del mundo; promueve el intercambio comercial, de inversiones, de innovación y tecnología con las regiones más competitivas del mundo; tiene el potencial para atraer 
a la región nuevas inversiones; y cuenta con ventajas competitivas en sectores como minería, recursos forestales, energía, agricultura, automotriz, pesca y manufactura. ${ }^{21}$ Por lo tanto, la Alianza se proyecta como un $h u b$ hacia otras regiones, para promover la liberalización. Este objetivo explícito requiere pues de reglas flexibles para los países en el manejo de sus relaciones comerciales.

Por lo expuesto, se observa que Argentina cuenta con compromisos asumidos en tratados internacionales que limitan la firma de acuerdos en materia comercial. Principalmente, el espacio del MERCOSUR es colocar precisiones para encaminar TLC con terceros países o grupos: deben hacerse en conjunto, a partir de la búsqueda de consensos en el bloque. El paraguas jurídico de la ALADI seguiría funcionando como el marco para encaminar estas acciones, ya sea con un MERCOSUR negociando conjuntamente o un MERCOSUR que pase a un esquema más típico de nuevo regionalismo.

Entre las opciones que cada tanto hacen eco entre algunos funcionarios, actores políticos y la prensa masiva se encuentran pues: la salida de Argentina del MERCOSUR -lo que traería un costo alto dado que gracias a la participación en este acuerdo regional, Argentina ha alcanzado colocar productos con mayor valor agregado en la región, principalmente con Brasil, profundizando un perfil exportador dual-; la remoción de la decisión del CMC No. 32/00 para habilitar la "flexibilidad" del bloque (y derivando en la destrucción de la unión aduanera); o bien la negociación de los cinco Estados Parte del MERCOSUR de un TLC con la Alianza del Pacífico (de la misma manera que se negocia con la UE o con países). Si bien aún no es posible avizorar qué opción tiene más asidero en la coyuntura actual, es posible desentrañar aquellos argumentos -en un hipotético caso de que Argentina no tuviera restricciones a la conclusión de un acuerdo con la Alianza- que se ponen en juego para avivar el debate de la vinculación con el Pacífico.

21. Ver: 〈https://alianzapacifico.net/〉. 


\section{Mitos o ventajas de participar en la Alianza para el Pacífico}

Suponiendo que existen posibilidades legales de incorporarse a la Alianza del Pacífico sin abandonar el MERCOSUR, queda aún en pie la pregunta de cuál sería el beneficio concreto de dicha acción y en qué se proyecta el atractivo que esta asociación comercial implicaría para la Argentina.

En principio, desde sus documentos fundacionales la Alianza del Pacífico destaca su carácter flexible y su voluntad de generar espacios para el desarrollo del libre comercio hacia sus socios, por un lado, y hacia el resto del mundo, por el otro, en tanto instrumento central del modelo de desarrollo de las naciones. En este sentido, refieren incluso al concepto de "regionalismo abierto" para expresar claramente su objetivo, entendiendo a los vínculos regionales como un escalón hacía una liberalización plena del comercio internacional.

Entonces, como marca distintiva, la Alianza del Pacífico promueve el libre mercado, con particular interés hacía las relaciones entre los socios y con la región del Asia Pacífico. En una segunda escala, plantea la cooperación en acciones de comercio exterior (con la meta de alcanzar un mercado integrado latinoamericano, MILA), la necesidad de avanzar hacia un esquema visado para promover el turismo con terceros países y ha encaminado acciones de movilidad científica y estudiantil sobre la base de políticas de cooperación internacional en educción superior e investigación, pero que no se encamina, aún, hacia la búsqueda de una política regional ni a la promoción de la identidad regional.

En este contexto, la vinculación con la Alianza del Pacífico traería a la Argentina nuevas oportunidades comerciales con los países miembros y, se supone, un nuevo vínculo comercial con terceros países, particularmente de la zona del arco del Pacífico, incluyendo en este proceso a los Estados Unidos -con quien todos los países de este bloque tienen acuerdos bilaterales de libre comercio-. Consecuentemente, resulta imperioso dividir las potencialidades que tendría un posible acercamiento entre Argentina y la Alianza en dos ejes: por un lado, las relaciones comerciales con los socios; por el otro, las potenciales oportunidades de un acercamiento conjunto a nuevos mercados. 
Las relaciones comerciales de Argentina con los socios de la Alianza para el Pacífico

En torno a las relaciones comerciales con los miembros de la Alianza para el Pacífico, un acercamiento formal al mismo no traería, en principio, grandes cambios. Tres instrumentos vigentes regulan las relaciones comerciales entre Argentina -y, en verdad, el conjunto del MERCOSUR ya que así fueron firmados aunque detalla condiciones diferenciadas para cada acuerdo bilateral- y los países sudamericanos de la Alianza; ya que México es un caso con ciertas diferencias. Esta situación se deriva de que, tras la puesta en marcha de la ALADI con la firma del Tratado de Montevideo de 1980, los países habían establecido diferentes acuerdos con preferencias comerciales que debieron ser renegociadas a partir de la creación del MERCOSUR -que fue inscripto como un acuerdo parcial de complementación económica (ACE) en ALADI, el ACE No. 18 entre Argentina, Brasil, Paraguay y Uruguay (depositado el 29 de noviembre de 1991)-.

Las relaciones con Perú se encuentran reguladas por el ACE No. 58, firmado en el año 2005. Este acuerdo plantea la culminación de la desgravación total del comercio entre ambas economías para el año 2018, aunque ya los plazos de llegada al arancel 0 para la mayoría de los productos fue alcanzado. Lo propio ocurre con el ACE No. 59, firmado con la República de Colombia en el año 2006, quedando algunos productos aún en proceso de liberalización. Finalmente con Chile se cuenta con un acuerdo de liberalización comercial desde al año 1996 (ACE No. 35), en pleno funcionamiento. De esta forma, en su gran mayoría y más allá de las salvaguardias y planteos de excepcionalidades siempre existentes, el comercio de bienes de Argentina con los socios sudamericanos de la Alianza del Pacífico se encuentra completamente liberalizado y sus efectos ya han sido procesados por nuestras economías.

De las tres economías, con Chile se realiza el comercio más importante, siendo el cuarto destino de las exportaciones argentinas en 2014, luego de Brasil, China y los Estados Unidos.

Perú se coloca como $17^{\circ}$ destino de las exportaciones de bienes de Argentina (representando el 1,6\% del total) y Colombia en el $24^{\circ}$ puesto $(1,2 \%$ del total $)$. 
- Gráfico 1. Exportaciones de Argentina en 2014 (selección de países/regiones) expresado en porcentaje

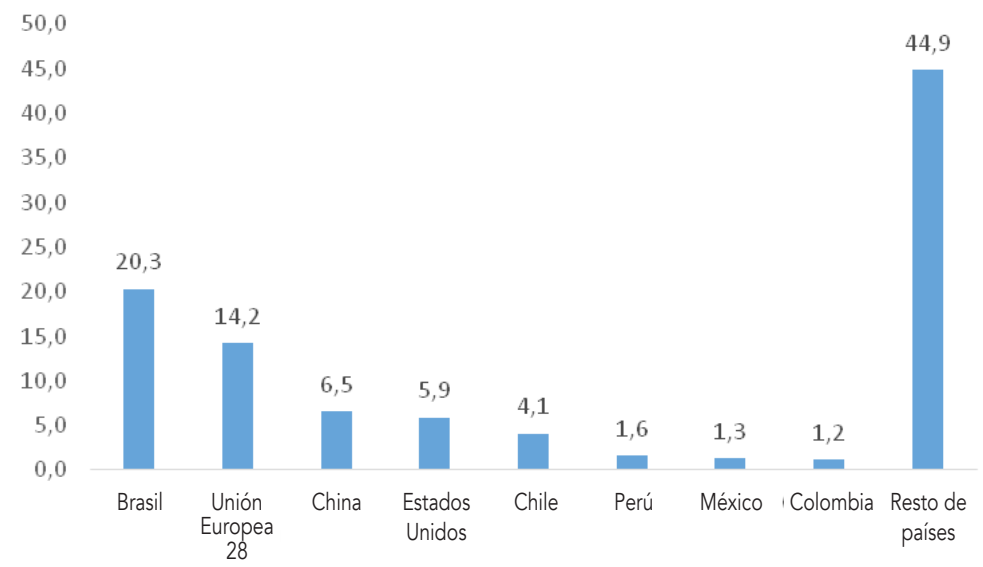

Fuente: Comtrade, Naciones Unidas -estadísticas de comercio internacional y OMC. Elaboración: autores.

Los datos anteriores muestran la exportación de bienes Argentina por país, no agrupa regiones (como es el caso de la Unión Europea). Si incorporamos esta variable (véase gráfico 1), se aprecia que la UE (de 28 países) es el segundo destino de las exportaciones de Argentina -luego de Brasil- con US \$ 9.701'500.000 millones (14,2\% del total). Así, China pasa al tercer puesto, Estados Unidos al cuarto y Chile al quinto.

Por su parte, con México aún se encuentra vigente el acuerdo automotriz ACE No. 55 de liberalización comercial, pese a numerosas marchas y contramarchas que lo paralizaron entre los años 2012 y 2015 . Actualmente, el acuerdo da lugar a un cupo de comercio con arancel 0 para, recién en 2019, volver a la expectativa de una liberalización sin restricciones. ${ }^{22}$

De los cuatro miembros de la Alianza del Pacífico, Argentina tiene actualmente déficit comercial con México (véase gráfico 2). En particular, en relación al sector automotriz, al cual le envió en 2014 vehículos utilitarios por valor de US \$ 209 millones y autopartes por US \$ 69 millo-

22. Télam. Economía. "Argentina y México prorrogan su acuerdo para el sector automotor". 〈http:// www.telam.com.ar/notas/201503/98232-argentina-mexico-autos-acuerdo.html». 
- Gráfico 2. Evolución de la balanza comercial Argentina-México (1993-2014) en millones de dólares

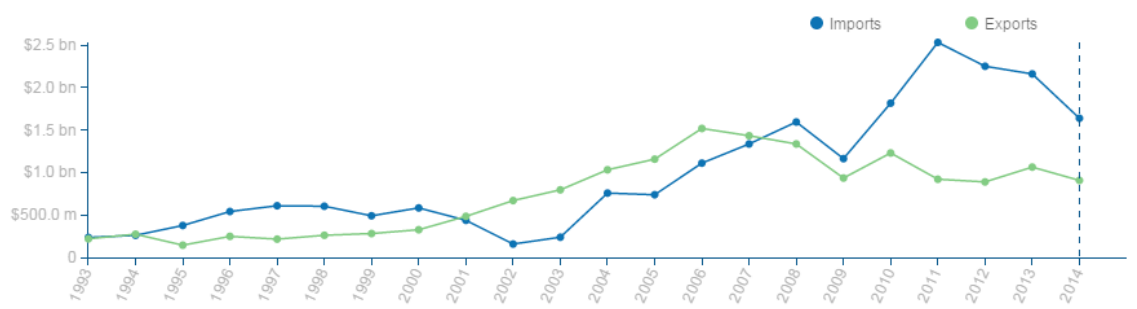

Fuente: Comtrade, Naciones Unidas-estadísticas de comercio internacional. Elaboración: autores.

nes, completando con esto el $28 \%$ de las exportaciones a ese país, seguido por artículos de cuero. Mientras, Argentina recibió del país norteamericano cerca de US \$ 500 millones en autos y autopartes, siendo este total apenas el 32\% de las exportaciones mexicanas a la Argentina. Observando el balance global, México se ubica como el séptimo proveedor externo de la Argentina con un total de US \$ 1.568 millones importados en 2014, y un déficit para nuestro país de más de US \$ 500 millones.

En este marco se entiende que un avance en la relación con la Alianza para el Pacífico traería en principio una mayor liberalización únicamente con México (dado el hecho de que con el resto de los países esta situación ya existe), lo que merece ser tomado con cuidado al menos en dos aspectos.

En primer lugar, el aspecto general de la balanza comercial con dicho país. Tal como se observa en el cuadro anterior, al momento de ser revisado el acuerdo automotriz, el déficit comercial llegaba a los US \$ 2.000 millones, hecho que excede incluso a la voluntad de los países y se vincula con la forma en que las grandes terminales organizan su producción a nivel mundial, siendo hoy México uno de los principales productores a nivel global particularmente a partir de la firma del NAFTA. ${ }^{23}$ Se entiende, entonces, que de avanzar en nuevos acuerdos es de esperar un incremento del déficit por esta razón.

23. Forbes México. "Los 10 países con mayor producción de autos del mundo". ‘http://www.forbes.com.mx/los-10-paises-con-mayor-produccion-de-autos-en-el-mundo/ ’. 
Adicionalmente, puede existir un argumento positivo en este comercio ya que, pese al déficit, una mayor integración sea positiva en términos de la propia industria automotriz Argentina, que ya en su relación con Brasil ha encontrado un nicho en la fabricación de Pick Ups y utilitarios, ampliando su mercado. Es de destacar que este intercambio automotriz es a la vez el intercambio comercial de mayor valor agregado con los países de la Alianza del Pacífico, dado que hacia el resto de las naciones, incluso a Chile, las exportaciones se componen principalmente de productos agrícolas, como son alimentos para animales y combustibles, que se encuentran en fuerte retroceso.

El segundo aspecto a tener en cuenta en el acercamiento argentino a la Alianza del Pacífico, además del desglose de la balanza comercial, refiere a la tendencia del comercio regional. A partir del análisis de los últimos años y agregando los primeros datos del 2015 nos encontramos con la confirmación de una tendencia ya observada, tal como lo demuestran los datos preliminares del informe del INTAL ${ }^{24}$ que plantea una caída de las exportaciones Argentinas a la región (Sudamérica) del $23 \%$ con respecto al año anterior, explicadas principalmente por el desplome del poder de compra de Brasil, pero también un descenso del 21\% de los montos exportados al resto de América Latina, en donde México aparece como un jugador central.

Por su parte, México cae un 10\% en relación al 2014 en sus vínculos con América Latina, centrado especialmente en sus exportaciones energéticas, en virtud de la caída del precio del petróleo. De esta forma, se acentúa el déficit comercial entre ambos países ${ }^{25}$ en un contexto de descenso general de las exportaciones generales que el Informe del INTAL ubica en un nivel apenas superior el obtenido en 2010:

Se estima que en 2015 el valor total de las exportaciones de mercancías de América Latina y el Caribe registrará una contracción de 14\%. Se trataría de

24. BID-INTAL. “Estimaciones de las Tendencias Comerciales de América Latina y el Caribe 2016”, en Giordano, P., Sector de Integración y Comercio. Washington: BID.

25. La Coordinadora de las Industrias de Productos Alimenticios de la República Argentina (COPAL) expresa en su informe de la "Relación del Comercio Exterior México-Argentina 2015" que para el mes de julio y con datos provisorios, las exportaciones Mexicanas a la Argentina duplican las exportaciones de sentido inverso. (informe disponible en «ttp://copal.org.ar/wp-content/uploads/2015/11/Presentacion-COMEX-Mexico-nov-2015.pdf)) 
- Tabla 1. Diez principales productos de Exportación argentinos a Chile 2013/2014

\begin{tabular}{|l|r|r|}
\hline \multicolumn{1}{|c|}{ Descripción del producto } & \multicolumn{2}{c|}{ Argentina exporta hacia Chile } \\
\cline { 2 - 3 } & Valor en 2013 & Valor en 2014 \\
\hline Todos los productos & 3 '906.689 & $2{ }^{\prime} 791.879$ \\
\hline Carne y despojos comestibles & 235.933 & 216.713 \\
\hline Cereales & 154.782 & 156.415 \\
\hline Grasas y aceites animales o vegetales; grasas alimenticias; ceras & 332.806 & 289.104 \\
\hline $\begin{array}{l}\text { Residuos, desperdicios de las industrias alimentarias; alimentos para } \\
\text { animales }\end{array}$ & 346.031 & 267.806 \\
\hline Combustibles minerales, aceites minerales y prod.de su destilación & 842.099 & 318.832 \\
\hline Aceites esenciales y resinoides;prep.de perfumeria,de tocador & 111.054 & 105.359 \\
\hline Materias plásticas y manufacturas de estas materias & 129.290 & 111.544 \\
\hline Papel, cartón; manufact. de pasta de celulosa, de papel/de cartón & 91.817 & 88.382 \\
\hline $\begin{array}{l}\text { Maquinas, reactores nucleares, calderas, aparatos y artefactos } \\
\text { mecánicos. }\end{array}$ & 103.473 & 86.699 \\
\hline $\begin{array}{l}\text { Vehículos automóviles, tractores, ciclos, demás vehic. terrestres, sus } \\
\text { partes }\end{array}$ & 218.572 & 135.671 \\
\hline
\end{tabular}

Fuente: Base de datos Comtrade de Naciones Unidas-estadísticas de comercio internacional. Elaboración: autores.

la mayor caída desde la crisis financiera internacional y de un resultado que llevaría el monto exportado a cerca de US \$ 915 mil millones, apenas por encima del 2010. Este será el tercer año consecutivo que las ventas externas de la región se reducen. A diferencia de los años precedentes, cuando se observó cierta heterogeneidad en los comportamientos subregionales, en 2015 la contracción abarca a todos los países. ${ }^{26}$

Es decir, que en virtud de lo analizado, en principio no parece haber argumentos sólidos que encuentren en un acercamiento en la Alianza del Pacífico una salida sustentable para el comercio exterior argentino en lo que respecta a una mayor liberalización del comercio con los socios. Esto se plantea en tanto y en cuanto el comercio con los socios sudamericanos del acuerdo ya se encuentra liberalizado y el comercio con México es actualmente deficitario y tiende a serlo aún más, incluso sin avanzar en un aumento de la liberalización de los vínculos, centrado sobre todo en las relaciones del sector automotriz cuyo equilibrio es producto de trabajosas negociaciones.

26. INTAL, Estimaciones de las Tendencias Comerciales de América Latina y el Caribe 2016. (Washington: Banco Interamericano de Desarrollo, 2015). 


\section{El comercio extra regional}

La Alianza del Pacífico exhibe en su tratado fundacional la intención de concentrar sus esfuerzos en la relación con el Área Asia-Pacífico, la cual se encuentra organizada en el Foro de Cooperación Económica de la Región, conocido como APEC, por su sigla en inglés, y dentro del cual los mandatarios del bloque han tenido numerosos encuentros. La APEC contiene en su interior a las dos principales economías del mundo (Estados Unidos y China), además de otras 19 naciones de las más variadas orientaciones políticas y económicas que van desde Vietnam a Brunei. ${ }^{27}$

Frente a esta complejidad, los países de la Alianza del Pacífico han incursionado en la firma de Acuerdos de Libre Comercio bilaterales con varios de estos Estados y la constitución de misiones comerciales comunes. Sin dudas Chile es quien lidera en relación a la firma de TLC; ${ }^{28}$ mientras que Colombia parece encontrarse más retrasada sin haber sido aún aceptada en APEC y solamente haber firmado un acuerdo con Corea del Sur. ${ }^{29}$ Entonces, se observa que la Alianza del Pacífico parece marcar más un rumbo que plantear estrategias rígidas frente a la negociación externa, llevando caminos comunes en ocasiones, pero dejando libre albedrío a los países ante la menor disonancia.

En este contexto, acercarse a la Alianza del Pacífico marcaría frente a los miembros de la Región Asia Pacífico una intención de Argentina, más que un compromiso concreto de vincularse con un sector del planeta relativamente desconocido para nuestra mirada atlántica. Por tanto, y dado el peso de la región, participar en el APEC sería una decisión lógica del país que de todas formas no depende de él mismo. En principio, la lógica de incorporación de nuevos miembros se reduce a aquellos que cuenten con fronteras al océano Pacífico (se negó el ingreso a la India formalmente por tal razón, aunque se escondían por detrás cues-

27. A comienzos de Marzo de 2016 son miembros de la APEC: Chile, Perú, México, Estados Unidos, China, Taiwán, Japón, Rusia, Australia, Nueva Zelandia, Brunei, Vietnam, Indonesia, Corea del Sur, Filipinas, Papúa Nueva Guinea, Malasia, Hong Kong, Singapur, Canadá y Tailandia.

28. El listado completo y las características de cada uno pueden ser revisados en la página de la Aduana chilena. 〈https://www.aduana.cl/tratados-y-acuerdos-de-libre-comercio/aduana/2007-0228/122217.html.

29. Los tratados firmados por Colombia pueden revisarse en la página del Ministerio de Industria y Comercio: 〈http://www.tlc.gov.co/publicaciones/5399/acuerdos_suscritos〉. 
tiones de equilibrio geopolítico); pero, incluso teniendo tal posibilidad, el ingreso no es automático -como demuestra el caso de Colombia, la cual tras pedir su ingreso en 1995, sigue esperando su aceptación ya que existe una moratoria al ingreso de nuevos socios hasta 2016, año en que podría finalmente ser incorporada-.

Suponiendo, entonces, esta lógica de gesto antes que de posibilidad concreta, pasemos a analizar someramente las ventajas o desventajas de un acercamiento a los países del Asia Pacífico bajo la lógica del libre comercio.

El primer dato a considerar es la evolución de la balanza comercial entre Argentina y los países del APEC teniendo en cuenta la necesidad imperiosa de aumentar el ingreso de dólares comerciales a la Argentina ante un proceso de restricción externa sumamente relevante.

En este punto, lo que se observa es un fuerte deterioro de la balanza comercial en los últimos cinco años, pasando de un superávit de casi 500 millones de dólares en el año 2010, a un déficit creciente de 6.981 millones de dólares en 2015, impulsado principalmente por el efecto precio relacionado con la caída de los valores de los commodities que exporta Argentina, pero también por un fuerte alza de las importaciones, particularmente de China (de US \$ 7.678 millones en 2010 a 11.783 en 2015) y en menor medida de Estados Unidos (de US \$ 6.125 a 7.706), y el área $\mathrm{ASEAN}^{30}$ (de US \$ 1.634 a 2.050).

Como se observa, la balanza comercial con la APEC es deficitaria en su conjunto, con fuertes déficits en el comercio con China y Estados Unidos, pero con espacios de superávit particularmente importantes con el área ASEAN.

En materia de valor agregado, el comercio más regresivo se da con China, con un 64\% de las exportaciones concentradas en el año 2014 en

30. La Asociación de Naciones del Sudeste Asiático (ASEAN por su sigla en inglés) está compuesto por Brunei, Camboya, Indonesia, Laos, Malasia, Myanmar, Filipinas, Singapur, Tailandia y Vietnam. 
. Gráfico 3. Balanza comercial Argentina / APEC 2010-2015 (en millones de dólares)

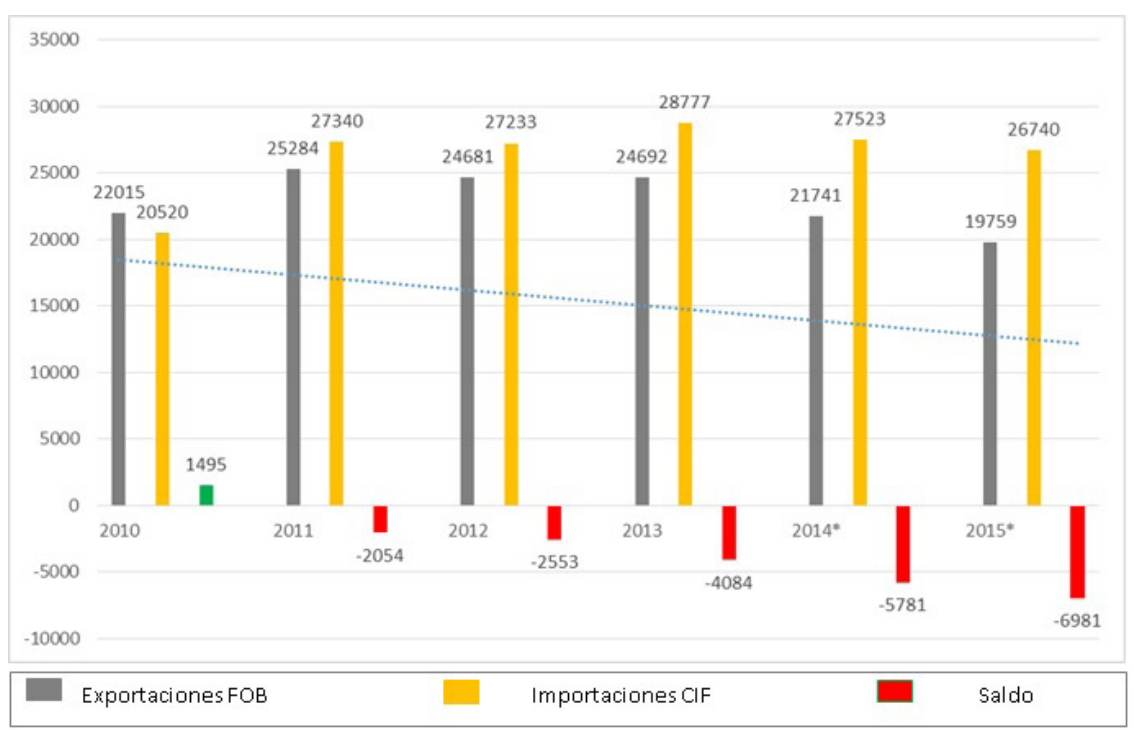

Fuente: INDEC Elaboración:autores.

porotos de soja; mientras las importaciones se dan mayormente en telefonía y productos electrónicos. Similar es el intercambio con el ASEAN, aunque aquí se trata de aceite de soja (y no de porotos), sosteniendo en nuestro país un paso más en la cadena de industrialización de la soja. Por caso, con Malasia, el 58\% de las exportaciones fue, en 2014, de pellets y aceite de soja y el $31 \%$ de maíz. ${ }^{31}$

Por su parte, con Estados Unidos, gran parte del comercio se encuentra vinculado al intercambio de combustibles, exportando la Argentina combustibles crudos e importando productos refinados. Sin embargo, por fuera de esto se pueden encontrar otros espacios de comercio, siendo importante la exportación de tubos de aluminio y otros metales, los vinos y los jugos de fruta, además de otras transacciones que muestran un comercio más diversificado en el marco de economías relativamente competitivas.

31. Comtrade, Naciones Unidas-estadísticas de comercio internacional. «https://comtrade.un.org/ ’ 
- Tabla 2. Balanza comercial Argentina / APEC desagregado por países (2010 y 2015)

\begin{tabular}{|c|c|c|c|c|c|c|}
\hline \multirow{2}{*}{$\begin{array}{c}\text { Zonas } \\
\text { económicas }\end{array}$} & \multicolumn{3}{|c|}{2010} & \multicolumn{3}{|c|}{$2015^{*}$} \\
\hline & $\begin{array}{c}\text { Exportación } \\
\text { FOB }\end{array}$ & $\begin{array}{c}\text { Importación } \\
\text { CIF }\end{array}$ & Saldo & $\begin{array}{c}\text { Exportación } \\
\text { FOB }\end{array}$ & $\begin{array}{c}\text { Importación } \\
\mathrm{CIF}\end{array}$ & Saldo \\
\hline & \multicolumn{6}{|c|}{ Millones de dólares } \\
\hline Chile & 4.493 & 885 & 3.608 & 2.398 & 717 & 1.681 \\
\hline México & 1.231 & 1.817 & -586 & 818 & 1.822 & -1.004 \\
\hline Canadá & 1.401 & 409 & 992 & 1.296 & 462 & 834 \\
\hline Estados Unidos & 3.669 & 6.125 & -2.457 & 3.423 & 7.706 & -4.283 \\
\hline ASEAN & 3.251 & 1.634 & 1.617 & 4.582 & 2.040 & 2.541 \\
\hline China & 6.117 & 7.678 & -1.561 & 5.388 & 11.783 & -6.395 \\
\hline Japón & 854 & 1.191 & -337 & 572 & 1.224 & -651 \\
\hline CEl & 658 & 442 & 216 & 550 & 697 & -147 \\
\hline Oceanía & 341 & 339 & 3 & 732 & 289 & 443 \\
\hline TOTAL & 22.015 & 20.520 & 1.495 & 19.759 & 26.740 & -6.981 \\
\hline
\end{tabular}

Fuente: INDEC. Dirección Nacional de Estadísticas del Sector Externo. Elaboración: autores.

\section{La mirada desde Chile y Colombia}

Ahora bien, todos los datos mencionados que indican una dificultad al menos en términos de intercambios con saldos positivos con el área del Pacífico están marcados en un contexto donde Argentina no ha suscripto acuerdos de libre comercio. Cabe entonces preguntarse si estos intercambios serían diferentes en un nuevo contexto de voluntad librecambista.

Por supuesto, realizar ese ejercicio de prospectiva siempre es dificultoso y propenso a las críticas. Más allá de las proyecciones y estimaciones, el devenir futuro nunca ésta escrito de antemano y, por tanto, el análisis prospectivo es de relativa utilidad. Otro abordaje posible también es el comparativo. Si vamos hacia un nuevo esquema de vinculación con el Pacífico, interrogar el cómo les ha ido en términos comerciales a aquellos que lo han hecho con anterioridad desde nuestra región resulta un interesante espejo desde donde mirarse, aun comprendiendo que hay cuestiones estructurales similares si bien otras muchas son diversas. Seguramente no será útil para observar en detalle los diversos mercados, pero al menos es posible analizar en términos generales los resultados de la balanza comercial y de diversificación de la canasta exportadora. 
- Gráfico 3. Balanza comercial Argentina/Chile/Colombia 2010-2014 (en millones de dólares)

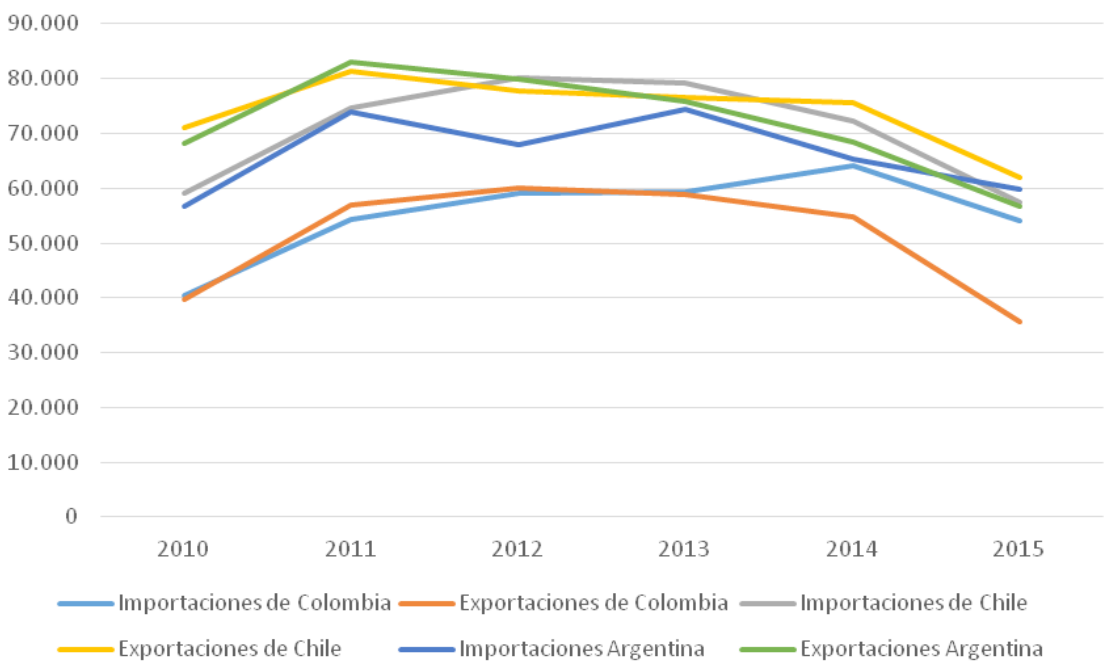

Fuente: INDEC, Servicio Nacional de Aduanas de Chile y Departamento Administrativo Nacional de Estadísticas de Colombia. Elaboración: autores.

Desde esta mirada lo primero que se puede observar es el recorrido similar de los mercados externos de los tres países, ${ }^{32}$ con un fuerte derrumbe de las exportaciones durante el año 2015, así como de las importaciones, aunque en menor medida, lo que llevo a la Argentina a entrar en déficit de su balanza comercial por primera vez en los últimos cinco años y amplió fuertemente el déficit de la balanza colombiana. Solamente Chile, con un pequeño margen, pudo mantener su superávit aunque en el marco general de descenso de las exportaciones. Este punto es interesante para notar que con acuerdos de libre comercio o sin ellos, las tendencias de la economía global afectan en forma similar las economías de los países sudamericanos.

En relación particular al análisis del vínculo con el Pacífico, entre Chile y Colombia se evidencia una importante diferencia en términos

32. Se toma Chile y Colombia por considerar dos economías diferentes dentro del esquema Pacífico. Agregar Perú no cambiaría en el análisis mucho (ya que lo que se observa son cuestiones comparativas entre economías) y complejizaría el análisis. 
de flujos comerciales. Más allá del volumen del vínculo (US \$ 77 mil millones de comercio bilateral entre APEC y Chile, en 2015, contra cerca de US \$ 50 mil millones en el caso colombiano), ${ }^{33}$ para el caso del país trasandino este vínculo es superavitario en más de 7 mil millones; mientras que para los cafetaleros el déficit asciende a más de 17 mil millones. Esta situación se explica por una balanza fuertemente negativa en el comercio bilateral con China (US \$ 7.769 mil millones de déficit en 2015) y Estados Unidos (US \$ 5.679 mil millones de déficit en ese mismo año) y la repetición del mismo signo con el resto de los demás países a excepción de Perú.

Claramente, la caída del precio del petróleo, principal producto de exportación colombiano explica fuertemente el desarrollo de esta balan$\mathrm{za}$, que de todas formas presentaba un comportamiento deficitario en años anteriores. Chile, por su parte, sin contar con una canasta de productos más heterogénea se ha visto menos afectado en relación al precio de su principal producto, el cobre y ha logrado mantener una balanza superavitaria con China (US \$ 3.313 millones en 2015) que compensa el déficit con Estados Unidos (US \$ 2.448 millones).

Otro dato importante de diferenciación es la trayectoria que Chile ha desplegado hacía el área Asia-Pacífico, siendo desde comienzo de los años 2000, el principal destino de sus exportaciones. Tal como plantea Fernández de Soto y Pineda Hoyos (2012) Japón, China y Corea se ubicaron desde comienzos de la década del 2000 entre los principales destinos, para concentrar en 2015 más del $40 \%$ del total de lo transado. Colombia, por su parte, en el año 2000 encontraba a China en el puesto 36 entre sus socios comerciales al concentrar apenas el $0,2 \%$ de sus exportaciones. En 2015, este país se ubica como el segundo destino de su comercio, detrás de los Estados Unidos, tanto en lo que se refiere a exportaciones como a importaciones. ${ }^{34}$

33. Servicio Nacional de Aduanas de Chile, https://www.aduana.cl/aduana/site/edic/base/ port/inicio.html y Dirección Administrativa Nacional de Estadísticas de Colombia 〈http:// www.dane.gov.co/>.

34. "Atlas de complejidad económica", Massachusetts Institute of Technology (MIT). «http://atlas. media.mit.edu/es/profile/country/col〉. 
- Gráfico 4. Comercio Chile/Colombia con principales países de APEC 2015 (en millones de dólares)

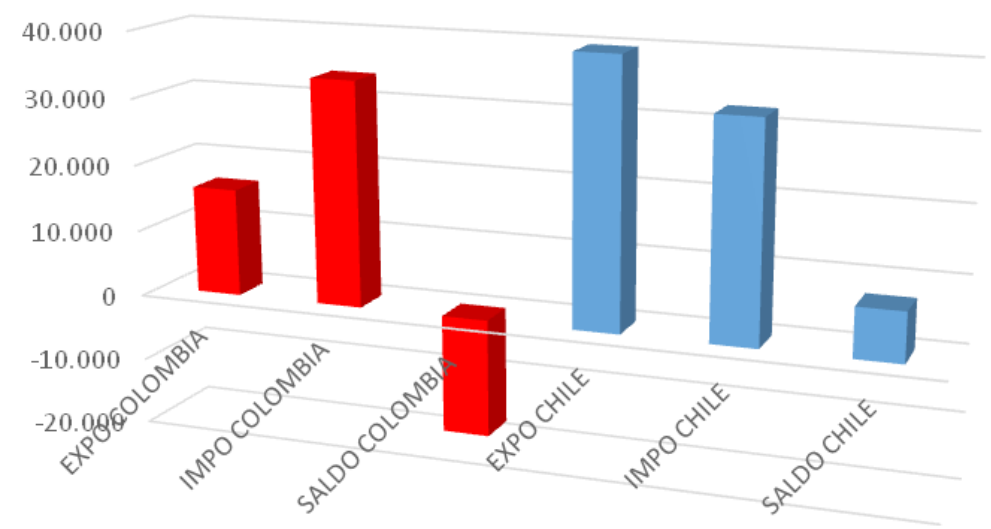

Fuente: Servicio Nacional de Aduanas de Chile y Departamento Administrativo Nacional de Estadísticas de Colombia. Elaboración: autores.

\section{- Gráfico 5. Comercio Colombia / APEC por países seleccionados (en millones de dólares)}

20.000

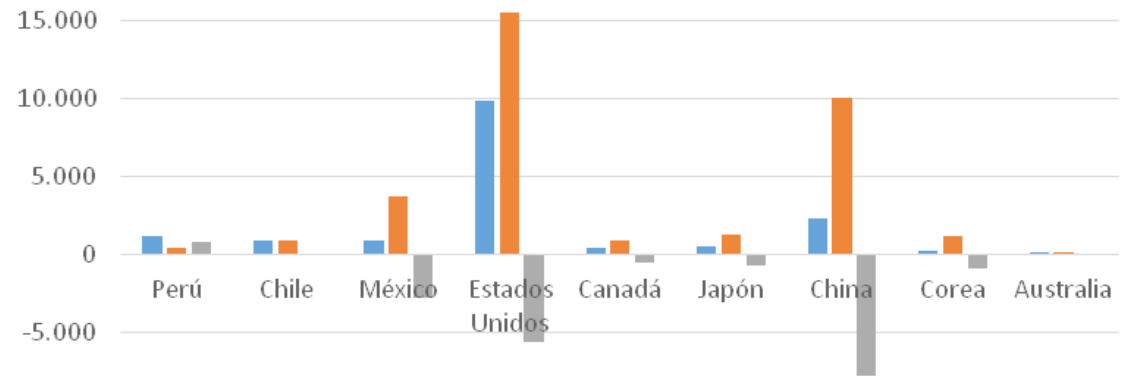

$-10.000$

$\square$ EXPO $\square I M P O \quad$ SALDO

Fuente: Departamento Administrativo Nacional de Estadísticas de Colombia y UN COMTRADE. Elaboración: autores. 
- Gráfico 6. Comercio Chile/ APEC por países seleccionados (en millones de dólares) 20.000

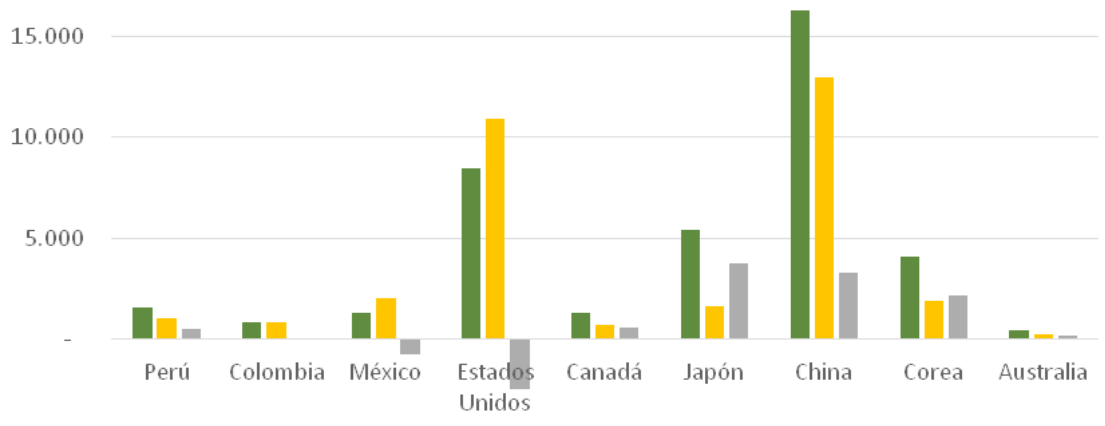

$-5.000$

Más cerca de Bogotá que de Santiago

En este contexto la expectativa argentina frente a un ingreso a la Alianza del Pacífico, parece tener que ubicarse más cerca de la realidad colombiana que la chilena, por más que esta última sea la que se usa de ejemplo por el dinamismo de su sector externo que explica cerca del $70 \%$ de su Producto Bruto Interno (PBI). En lo inmediato, la lejanía de Argentina de los mercados asiáticos, por fuera del eje sojero chino, encuentra un vínculo con el proceso de inserción colombiano en la región, recién despuntando en los últimos años y relativamente alejado de los espacios institucionales de gobernanza comercial del Pacífico.

Es decir que, si bien a largo plazo la vinculación más estrecha con dicha zona puede plantear mejoras en la balanza comercial, lo esperable en el corto y mediano plazo es un aumento sostenido del déficit en términos de flujos, especialmente en la medida en que los precios de los commodities no repunten; y más aún en términos de calidad del comercio, dado que para todos los países de la región, incluso para Chile, el intercambio es principalmente el modelo clásico de manufacturas por materias primas. De hecho, con los países asiáticos (y principalmente 
con China) este modelo se encuentra aún más definido que con los Estados Unidos, donde la complementación en la producción de diferentes productos naturales genera una mayor diversificación del comercio.

Negar a Asia-Pacífico es posiblemente un intento infructuoso y erróneo. Pero ver allí la resolución inmediata de los problemas argentinos de la balanza comercial es poner en la idea del libre comercio una valoración alejada de cualquier precaución mínima en torno al desarrollo y equilibrios de los distintos sectores de la economía nacional.

Posiblemente un ingreso a la Alianza para el Pacífico aumente los flujos comerciales, pero esto no redundará, al menos en términos comerciales, en una mejora en relación a la escases de divisas. Motivo por el que resulta importante, al menos en primera instancia, dejar de lado en términos discursivos este argumento. Seguramente existan muchos otros, discutibles políticamente (atracción de inversiones, alineamiento con los Estados Unidos, cercanía a los mercados); pero en términos concretos, sostener la alianza del MERCOSUR y avanzar desde allí hacía otros mercados (Latinoamérica, preferentemente; luego, Europa e, incluso, Estados Unidos) promete mejores perspectivas que la búsqueda de ser quien no se es.

En este marco, retomando la estrategia de la comparación: ¿en qué beneficia la Alianza para el Pacífico puntualmente a Colombia y como nos veríamos incluidos en un progreso similar? Trujillo Acosta (2014) parece acercar una respuesta planteando que

la Alianza del Pacífico facilita [a Colombia] profundizar sus relaciones comerciales sin generar tensiones con otros países ni otros grupos regionales [...] y diversificar sus relaciones en términos geográficos y temáticos a partir de las acciones conjuntas en el marco de la [Alianza del Pacífico], particularmente con los países del Asía-Pacífico. ${ }^{35}$

La idea de la flexibilidad y la potencialidad del trabajo conjunto sin tensiones parece entonces ser la cuestión clave. Y posiblemente lo sea. Pero en el caso argentino, la presencia del MERCOSUR impide la idea

35. Iván Trujillo, “Sobre las ventajas de la Alianza del Pacífico para Colombia”, Prolegómenos, No. 33 (2014): 159-172. 
de este planteo que entiende a la Alianza del Pacífico poco más que como un espacio de cooperación comercial y marketing conjunto.

En definitiva, entonces, los números muestran una realidad fáctica poco favorable a dicho acercamiento; $y$ las potencialidades asociadas a la flexibilidad se encuentran al menos al día de hoy fuertemente condicionadas por el MERCOSUR, por lo cual el acercamiento argentino a la Alianza del Pacífico resulta, en principio, una iniciativa no recomendable.

Quedan, como siempre, opciones (como esbozamos antes): que el MERCOSUR entero se acerque a la Alianza, con lo cual uno de los dos bloques dejará de ser lo que hoy es. Esta es la primera y potencialmente factible alternativa, dados los cambios de visión política que están experimentando los países de dicho proceso de integración. La discusión aquí será, por un lado, cómo sostener los sectores de la economía argentina ligados a Brasil y que constituyen una porción importante del conglomerado de exportaciones manufacturadas -tanto manufacturas de origen industrial (MOI) como agrícola (MOA)- argentinas. Pero, por el otro, también cómo sostener al conjunto de los sectores asociados al mercado interno (textiles, zapatos, juguetes, por ejemplo), que quedarían fuertemente expuestos ante la competencia asiática.

Esta situación en todo caso, se aleja del análisis concreto que pretende este artículo y que busca analizar en forma general el escenario actual para un acercamiento de la Argentina a la Alianza del Pacífico.

\section{Reflexiones finales}

En este trabajo buscamos indagar los límites y posibilidades del ingreso a la Argentina a la Alianza del Pacífico, explorando las supuestas ventajas que este acercamiento comercial conllevaría. Para vislumbrar esto, el ejercicio propuesto fue analizar dos ámbitos: primero, un estudio de las restricciones formales legales para la Argentina -Estado Parte del MERCOSUR- de integrar dos esquemas de integración regional; segundo, una indagación de los potenciales beneficios materiales que recibiría Argentina a partir del relacionamiento con la Alianza del Pacífico. En este último caso, se desplegó un pequeño ejercicio comparativo en vistas a observar la situación por país de en qué medida y a qué sec- 
tores económicos beneficia la Alianza, de manera de extrapolar las conclusiones al caso argentino.

Respecto del análisis formal-legal, como Estado Parte del MERCOSUR -que es una unión aduanera y que, a la vez, cuenta con una cláusula especial que prohíbe a los países la negociación de preferencias arancelarias con terceros- Argentina se encuentra jurídicamente limitada a un acercamiento formal sin el consenso de los restantes socios MERCOSUR con la Alianza. Por esto se plantean al menos tres escenarios prospectivos:

Escenario 1. Salida de Argentina del MERCOSUR. La primera posibilidad -la menos conveniente también porque dejaría de lado la acumulación e intensidad de los intercambios y del relacionamiento de nuestro país en la región- es la salida de Argentina de un MERCOSUR que "constriñe" la búsqueda de un esquema de inserción internacional competitivo, firmando tratados de libre comercio con diferentes países y grupos de países -la mayoría de estos de tipo asimétricos. La salida del MERCOSUR igual, implicaría, la renegociación de los ACE en el marco de la ALADI, con los demás Estados Parte, así como con los Asociados del MERCOSUR. Es el escenario menos probable porque no solamente traería un costo político elevado, sino que Argentina perjudicaría el perfil exportador con mayor valor agregado que ha logrado construir desde la creación del MERCOSUR, y en especial con Brasil.

Escenario 2. Flexibilización del MERCOSUR. Una posibilidad con bastante asidero dada la nueva correlación de fuerzas en los países de la región -pasaje del ciclo post hegemónico a un nuevo (¿renovado?) ciclo neoliberal- es contar con un MERCOSUR más liviano y flexible que permita a sus socios el manejo de sus relaciones comerciales externas de manera unilateral -recuperando los escasos márgenes de soberanía que fueron puestos en común-. Esto significaría, primero, dejar sin efecto la decisión del CMC No. 32/00 y, segundo, terminar de sepultar la unión aduanera para ceñir al espacio regional a una zona de libre de comercio. En este marco, por un lado, los países del MERCOSUR no solamente podrían comenzar a negociar con diversos países, incluyendo a los de la Alianza del Pacífico, con los cuales, además, podría negociar -por otro lado- en el marco de la ALADI. Este escenario generaría, a la vez, algo similar a lo sucedido tras el No al ALCA: la competencia de los países por buscar firmar acuerdos de liberalización comercial con las po- 
tencias económicas; léase, con los Estados Unidos. Reavivando así el esquema de ejes de rayos y complejizando aún más el spaghetti bowl.

Escenario 3. Acuerdo MERCOSUR-Alianza del Pacifico. Un escenario intermedio desde el punto de vista formal es cerrar el inconcluso proceso de convergencia entre la CAN y el MERCOSUR que luego derivó en la UNASUR: hacer converger las dos zonas económicas de América del Sur, ahora bajo la cartografía de la Alianza del Pacífico y del MERCOSUR. En la práctica, exceptuando el acuerdo con México (que tiene sus peculiaridades), con los demás países de la Alianza, los ACE ya firmados (y su estatus de Estados Asociados) tornarían -en este nuevo contexto donde las diferencias ideológicas de otrora se licúan ante el concierto aperturista- más factible el escenario para la negociación y la conclusión de una zona de libre comercio sudamericana. Desde aquí, a su vez, los países del MERCOSUR -y Argentina que es el caso que nos compete- podrían desplegar la búsqueda de relacionamiento con otros espacios económicos, como el Arco del Pacífico.

Pues bien, en el segundo nivel de análisis, se destacan las siguientes conclusiones. Entendiendo la posibilidad del tercer escenario planteado como el más posible, queda la pregunta de la lógica de acercamiento al eje pacífico. Es aquí donde en la actualidad se pueden encontrar más previsiones que oportunidades. En un todo, el comercio con el mundo asiático se expresa hoy en dos premisas: déficit comercial y baja calidad del comercio en el sentido de reproducir la lógica de exportación de materias primas e importación de productos manufacturados.

Ciertamente, el componente del déficit se ajusta al efecto precio de las commodities y particularmente de la soja. En ese marco avanzar en este sentido queda condicionado al pronóstico futuro de este mercado, sin cambiar por ello el modo de relacionamiento. Pero este marco del déficit a corto plazo no es un dato menor en un contexto de aguda restricción externa por parte de la Argentina. De hecho, un aumento de la liberalización comercial podría traer (como se ha expresado en la experiencia histórica) un aumento de los flujos, generando un déficit aún mayor.

Pero aún con un cambio en la tendencia de los precios, quedaría la duda, en este marco estructural de las relaciones comerciales argentino - asiática, si sería beneficioso para un modelo de desarrollo sostenible la apertura comercial con este espacio geográfico. 
En este sentido, la profundización del eje latinoamericano parece seguir siendo una estrategia más firme aunque los flujos sean menores. Confiar en la recuperación de Brasil, abriendo nuevos espacios con los otros países tiende a consolidar una economía más diversificada e industrializada. Allí, la Alianza del Pacífico puede jugar un papel interesante en aceitar las relaciones con los países pacíficos sudamericanos y ampliar las relaciones con México, economías de desarrollo relativo similar y con espacios de complementariedad más beneficiosos.

En todo caso, es de esperar que la fascinación mítica con el área pacifico no redunde en un enfriamiento del relacionamiento con Brasil, el resto de América e incluso con los Estados Unidos, país con el cual el comercio, aunque fuertemente deficitario, es más diversificado.

Finalmente, en este trabajo no hemos estudiado los procesos de liberalización del sector de servicios para analizar el mapa de los ganadores y perdedores de este proceso de ser encaminado por nuestro país con determinados países y grupos de países. Esto merece un análisis en profundidad que excedía el objetivo de nuestro trabajo. No obstante, destacamos que es una discusión a la que habrá de prestar especial atención en los acuerdos que se estén concluyendo.

A modo de cierre, vale la pena retomar el título del trabajo y plantear que no sería positivo volver a sucitar propuestas ya discutidas para nuevos escenarios. El péndulo de la discusión de nuestros países sudamericanos, que se inclinan de derecha a izquierda por etapas, conspira contra la construcción de una mirada coherente en torno a nuestro vínculo frente al mundo. Uno podría decir que son doscientos años de puja entre modelos de desarrollo diferenciados, y seguramente no estaría alejado de la realidad. En este mismo sentido encontrar algún marco de síntesis, sin dudas, sigue siendo el desafío.

\section{Bibliografía}

Baier, Scott, Bergstrand, Jeffrey, y Egger, Peter. “The New Regionalism: Causes and consequences". Economie internationale, No. 1 (2007): 9-29.

Bhagwati, Jagdish. US trade policy: The infatuation with FTAs. Columbia University Academic Commons. 〈http://hdl.handle.net/10022/AC:P:15619».

Bhagwati, Jagdish, y Panagariya, Arvind. "Preferential trading areas and multilateralism-strangers, friends, or foes". En Jagdish Bhagwati, P Krishna y Arvind Pana- 
gariya, Trading Blocs: Alternative Approaches to Analyzing Preferential Trade Agreements. Cambridge: MIT Press, (1999): 33-100.

BID. "El nuevo regionalismo en América Latina". En Banco Interamericano de Desarrollo, Mas allá de las fronteras: el nuevo regionalismo en América latina. Buenos Aires: BID, (2002): $27-65$.

CEPAL. Transformación productiva con equidad. La tarea prioritaria de América Latina y el Caribe en los años noventa Santiago de Chile: CEPAL, 1990.

Fernández de Soto, Guillermo, y Pineda Hoyos, Saúl. El Pacífico. La inserción atrasada. La relación de Colombia con el Asia-Pacífico en el contexto de América Latina. Bogotá: Consejo Colombiano de Relaciones Internacionales 2012.

Gomez-Mera, Laura, y Molinari, Andrea. "Overlapping institutions, learning, and dispute initiation in regional trade agreements: evidence from South America". International Studies Quarterly, 58, No. 2 (2014): 269 - 281.

INTAL. Estimaciones de las Tendencias Comerciales de América Latina y el Caribe 2016. Washington: Banco Interamericano de Desarrollo, 2015.

Malamud, Andrés. Overlapping regionalism, no integration: conceptual issues and the Latin American experiences, 2013.

Malamud, Carlos. La Alianza del Pacífico: un revulsivo para la integración regional en América Latina Madrid: Real Instituto Elcano, 2012.

Motta Veiga, Pedro da, y Ríos, Sandra. O regionalismo pós-liberal, na América do Sul: origens, iniciativas e dilemas. Santiago de Chile: CEPAL, 2012.

Peña, Félix. “¿Cuál es el verdadero problema del "spaghetti bowl”?: Proliferación de acuerdos preferenciales en un sistema comercial global debilitado". Newsletter sobre relaciones comerciales internacionales, abril (2007). 〈http://www.felixpena.com. $\mathrm{ar} /$ index.php?contenido=negociaciones\&neagno=informes $/ 2007-04$.

Perrotta, Daniela. MERCOSUR Brand: regionalism and higher education. Trabajo presentado en Regionalism, Norm Diffusion and Social Policy: dealing with Old and New crises in Europe and Latin America, Berlín, 2013.

-----. "Tres modelos de internacionalización en disputa en el regionalismo sudamericano. En Red de Internacionalización de la Educación Superior en el Mercosur". Internacionalización de la Educación Superior en el Mercosur. Tandil: CEIPIL, 2014.

Perrotta, Daniela, y Porcelli, Emanuel. "Mercosur 25 años: desafíos en su nueva etapa". Márgenes. Revista de Economía Política, No. 2 (2016): 51-86.

Riggirozzi, Pia, y Tussie, Diana. "The Rise of Post-Hegemonic Regionalism in Latin America. En Pia Riggirozzi y Diana Tussie, editor, The Rise of Post-Hegemonic Regionalism. The case of Latin America. Dordrecht: Springer. Vol 4 (2012): 1-16.

Sanahuja, José Antonio. "Del 'regionalismo abierto' al 'regionalismo post liberal'. Crisis y cambio en la integración en América Latina y el Caribe". En Laneydi Martínez, Lázaro Peña y Mariana Vazquez, editor, Anuario de la integración regional de América Latina y el Gran Caribe 2008-2009. Buenos Aires: Coordinadora Regional de Investigaciones Económicas y Sociales-CRIES, 2008.

-----. "Post-liberal Regionalism in South America: The case of UNASUR". EUI Working Papers, RSCAS 5 (2012): 1-31. 
Scharpf, Fritz. Notes toward a theory of multilevel governing in Europe. Scandinavian, , No. 1 (2001): 1-26.

Trujillo Acosta, Iván Alejandro. "Sobre las ventajas de la Alianza del Pacífico para Colombia". Prolegómenos, No. 33 (2014): 159-172. 